Research Article

\title{
Prediction of Dynamic Modulus of Hot Mix Asphalts with Reclaimed Asphalt Pavement
}

\author{
Zahid Hossain (iD) ${ }^{1}$ and Musharraf Zaman (D) $^{2}$ \\ ${ }^{1}$ Arkansas State University, P.O. Box 1740, Jonesboro, AR 72467, USA \\ ${ }^{2}$ The University of Oklahoma, 202 West Boyd Street, CEC \#107, Norman, OK 73019, USA \\ Correspondence should be addressed to Zahid Hossain; mhossain@astate.edu
}

Received 4 February 2020; Revised 28 September 2020; Accepted 3 October 2020; Published 24 October 2020

Academic Editor: Fan Gu

Copyright (c) 2020 Zahid Hossain and Musharraf Zaman. This is an open access article distributed under the Creative Commons Attribution License, which permits unrestricted use, distribution, and reproduction in any medium, provided the original work is properly cited.

\begin{abstract}
This study evaluated the viscoelastic properties of a performance grade (PG) binder blended with different percentages of binders recovered from reclaimed asphalt pavement (RAP) for conditions (materials, climate, and specifications) prevailing in Oklahoma. The viscoelastic properties of the blended binders were then used to estimate dynamic modulus $\left(E^{*}\right)$ values of the new mixes with RAP by using the Witczak model through time-temperature superposition (TTS) principles. The recovered binder from RAP was found to be significantly stiffer than the virgin binder (PG 64-22). The addition of RAP increased the complex modulus $\left(G^{*}\right)$ of the base binder, so did the $E^{*}$ of the corresponding mix. The creep stiffness resistance of the asphalt binder at low service temperatures decreased with the addition of RAP. With up to 10\% RAP binder, no notable changes were observed in the viscosity and PG grade of the virgin binder. With $25 \%$ and $40 \%$ RAP binder, the PGs of the blended binders were found to be PG 70-16 and PG 76-16, respectively. It was observed that the $E^{*}$ master curves predicted from PGs of the blended binders were in close agreement with those estimated from the laboratory-measured $E^{*}$ data. The dynamic shear rheometer (DSR) data of rotational thin film oven (RTFO)-aged blended binders predicted significantly lower $E^{*}$ values compared to the measured ones. The $E^{*}$ values predicted from rotational viscosity (RV) test data were found to be higher than the measured $E^{*}$ values. The findings of this study are expected to provide transportation professionals with a better understanding of new mixes with high RAPs.
\end{abstract}

\section{Introduction and Background}

Asphalt concrete $(\mathrm{AC})$ is the most recycled product in the US due to its beneficial effects on reducing the consumption of virgin materials and providing increased environmental stewardship. Significant efforts have been made by federal and state agencies as well as various focus groups to promote the use of high reclaimed asphalt pavement (RAP) content by working with state Departments of Transportation (DOTs) on field projects, which demonstrate the performance of high RAP mixes [1]. Even though the beneficial effects are high, several state agencies including the Oklahoma Department of Transportation (ODOT) do not allow the use of "high RAP" in mixes for their roadways. The current practice of ODOT is to allow a maximum of $25 \%$ RAP in base courses and none in surface courses. These limits are significantly lower than the maximum allowable limits nationally and are also lower than neighboring states [2]. This is partly because of the lack of mechanistic performance data and specifications of RAP [3-5]. For a greater mechanistic analysis and design of asphalt concrete (AC) pavements, a majority of state DOTs including ODOT have implemented or are in the process of implementing the Mechanistic-Empirical Pavement Design Guide (MEPDG), which is less empirical than the widely used 1993 American Association of State Highway and Transportation Officials (AASHTO) Guide Guides for Pavement Structures [6].

The MEPDG evaluates pavement performance by using local material properties as input. In the hierarchical approach of the MEPDG, laboratory test data of asphalt binders and asphalt mixes are required to obtain the highest reliability (Level 1). At this level, dynamic shear modulus 
$\left(G^{*}\right)$ and phase angle $(\delta)$ values of the asphalt binder are combined with the dynamic modulus $\left(E^{*}\right)$ values of the mixes to estimate $E^{*}$ master curves for the design life of the pavement [17]. At the intermediate level (Level (2)) the aforementioned asphalt binder's data is combined with the volumetric properties of the mix to evaluate the performance of the pavements. At Level 3, the volumetric properties of the mix along with the performance grade (PG) or viscosity of the asphalt binder are used as input. The findings of some of the relevant studies on the performance of RAP binders and mixes are summarized below.

Soupharath [7] studied the rutting resistance of asphalt binder containing RAP for conditions prevailing in Rhode Island. In this study, a PG 64-22 binder was blended with different amounts (0 to 100\%) of RAP binders. The dynamic shear rheometer (DSR) test data was used to evaluate the blended asphalt binders at high temperatures. It was found that the addition of a RAP binder generally increased the resistance to rutting.

Lee et al. [8] investigated the rheological and mechanical properties of blended asphalt binders (PG 58-28 and PG 6422) containing different percentages $(0,10,20,30,40,50,75$, and $100 \%$ by weight) of RAP binders. DSR tests performed at various temperatures showed a good linear relationship between log-log rheological parameters and the amount of RAP. The BBR tests performed at low service temperatures $\left(-6,-12,-18\right.$, and $\left.-24^{\circ} \mathrm{C}\right)$ showed an increase in creep stiffness and a decrease in the $m$ value for all temperatures as the amount of RAP content increased, indicating that the addition of the RAP content reduced the binder's resistance to low-temperature cracking.

In a laboratory study, $\mathrm{Li}$ et al. [9] investigated the performance of ten (10) asphalt mixes, including two different RAP sources, at three different RAP contents $(0,20$, and 40\%) and two different asphalt binders (PG 58-28 and PG 58-34). The $G^{*}$ and the stiffness of asphalt mixes were found to increase with the addition of RAP. It was reported that the asphalt mixes containing RAP had higher $E^{*}$ values than the virgin mixes. A stiffer binder was found to result in higher $E^{*}$ values for both the control and the RAP-modified mixes. The experimental data obtained from this study indicated that using $20 \%$ RAP did not significantly affect the performance of the resulting mixes. Mixes containing 40\% or more RAP had much larger effects on their performance. It was also observed that the RAP source was not a significant factor for the $E^{*}$ values at low temperatures, although it significantly affected $E^{*}$ values at high temperatures.

Daniel and Lachance [10] evaluated the effects of RAP on $E^{*}$ values of hot mix asphalt (HMA) with an unmodified PG 58-28 binder and two types of RAP, namely, a processed RAP and an unprocessed RAP. A total of four mixes containing different percentages of RAP $(0,15,25$, and $40 \%)$ were tested at $14^{\circ} \mathrm{F}\left(-10^{\circ} \mathrm{C}\right), 32^{\circ} \mathrm{F}\left(0^{\circ} \mathrm{C}\right), 50^{\circ} \mathrm{F}\left(10^{\circ} \mathrm{C}\right), 68^{\circ} \mathrm{F}$ $\left(20^{\circ} \mathrm{C}\right)$, and $86^{\circ} \mathrm{F}\left(30^{\circ} \mathrm{C}\right)$ at loading frequencies ranging from 0.1 to $30 \mathrm{~Hz}$. The $E^{*}$ values of the processed RAP mixes increased from the control ( $0 \% \mathrm{RAP}$ ) to $15 \% \mathrm{RAP}$, while the $25 \%$ and $40 \%$ RAP mixes had $E^{*}$ curves similar to that of the control mix. Further, it was reported that the $25 \%$ and $40 \%$
RAP mixes had higher voids in mineral aggregate (VMA) and voids filled with asphalt (VFA) values than those for the control and other mixes containing 15\% RAP, indicating that softer mixes resulted in low $E^{*}$ values.

Cross and Jakatimath [11] measured the $E^{*}$ of 21 HMA mixes containing 25\% RAP throughout Oklahoma. Each mix was prepared with three different binders, namely, PG 64-22, PG 70-28, and PG 76-28, at the optimum binder content. The HMA samples were compacted for a target air void of $4.5 \pm 1 \%$. The samples were tested for $E^{*}$ at $40^{\circ} \mathrm{F}$ $\left(4.4^{\circ} \mathrm{C}\right), 70^{\circ} \mathrm{F}\left(21.1^{\circ} \mathrm{C}\right), 100^{\circ} \mathrm{F}\left(37.8^{\circ} \mathrm{C}\right)$, and $130^{\circ} \mathrm{F}\left(54.4^{\circ} \mathrm{C}\right)$ at loading frequencies of $25 \mathrm{~Hz}, 10 \mathrm{~Hz}, 5 \mathrm{~Hz}, 1 \mathrm{~Hz}, 0.5 \mathrm{~Hz}$, and $0.1 \mathrm{~Hz}$ at each temperature in accordance with AASHTO TP 62. The results showed that at intermediate test temperatures, $70^{\circ} \mathrm{F}\left(21.1^{\circ} \mathrm{C}\right)$ and $100^{\circ} \mathrm{F}\left(37.8^{\circ} \mathrm{C}\right)$, mixes containing RAP were not significantly different from the virgin mixes prepared with a PG 64-22 binder. It was also found that $25 \%$ RAP in a mix had the same effect on the measured $E^{*}$ as virgin mix prepared with one PG grade higher binder. In another study, McGraw et al. [12] examined the effect of RAP on $E^{*}$ of 17 HMA mixes containing various amounts $(0,10,15,25$, and $30 \%)$ of RAP using two types of binders (PG 58-28 and PG 51-34). It was found that the $E^{*}$ increased when increasing RAP content with the differences being more pronounced at lower frequencies (high temperatures). The increase in $E^{*}$ was noticeably higher in the mix containing 30\% RAP than that of the control mix ( $0 \%$ RAP). Similar observations were made by Loria et al. [13] in their corresponding study, which evaluated the $E^{*}$ of HMA mixes containing $15 \%$ and $50 \%$ RAP. Other researchers (e.g., $[14,15])$ also reported an increased $E^{*}$ with an increase in RAP content in the respective studies.

Islam et al. [16] studied the rutting and low-temperature properties of RAP mixes with up to $35 \%$ RAP. These researchers reported that RAP mixes were expected to exhibit less rut than virgin mixes. On the other hand, RAP mixes were expected to be more susceptible to low-temperature cracking.

El-Badawy et al. [17] evaluated 75 different HMA mixes at different test conditions, which generated $3,720 E^{*}$ values. These $E^{*}$ data along with the corresponding mix volumetric and binder's rheological data were used to develop neural network (NN) models to predict $E^{*}$ of other mixes. It was reported that three parameters, namely, $G^{*}, \delta$, and Brookfield viscosity, yielded more accurate $E^{*}$ values in the $\mathrm{NN}$ predictive models.

A recent study by Elkashef et al. [18] attempted to predict binder properties from mixture test data. These researchers estimated $G^{*}$ values with different percentages of RAP binder and reported that the predicted values from the model were found to be consistently higher than the measured $G^{*}$ values of the chemically extracted binders.

1.1. Witczak Model. To estimate the $E^{*}$ values of a mix, the Witczak model [19] adopted in the MEPDG is commonly used. In this model (1), the asphalt binder viscosity $(\eta)$ is the measurement of the RV test of the RTFO-aged binder: 


$$
\begin{aligned}
\log E^{*}= & -1.25+0.029 P_{200}-0.0018\left(P_{200}\right)^{2}-0.0028 P_{4}-0.058 V_{a}-0.822\left(\frac{V_{\text {beff }}}{V_{\text {beff }}+V_{\text {a }}}\right) \\
& +\frac{3.872-0.0021 P_{4}+0.004 P_{38}-0.000017\left(P_{38}\right)^{2}+0.0055 P_{34}}{1+e^{(-0.603313-0.313351 \log (f)-0.393532 \log (\eta))}},
\end{aligned}
$$

where $E^{*}$ is the dynamic modulus of the mix, $10^{5} \mathrm{psi} ; \eta$ is the viscosity of binder, $10^{6}$ Poise; $f$ is the loading frequency, $\mathrm{Hz} ; V_{\mathrm{a}}$ is the air void content, \%; $V_{\text {beff }}$ is the effective asphalt content, \%; $P_{34}$ is the cumulative \% retained on $3 / 4$ in sieve; $P_{38}$ is the cumulative \% retained on $3 / 8$ in sieve; $P_{4}$ is the cumulative \% retained on \#4 sieve; and $P_{200}$ is the \% passing \#200 sieve.

The $\eta$ value can also be determined by using (2) if the binder's $G^{*}$ and $\delta$ values are known:

$$
\eta=\frac{G^{*}}{10}\left(\frac{1}{\sin \delta}\right)^{4.8628} \text {. }
$$

Once the $\eta$ value is determined, the ASTM A and VTS parameters, shown in (3), can be found by a linear regression analysis after a log-log transformation of the viscosity (in $\mathrm{cP}$ ) and $\log$ transformation of the temperature $\left(T_{R},{ }^{\circ}\right.$ Rankine) data:

$$
\log \log \eta=A+\mathrm{VTS} \log T_{R} .
$$

Using time-temperature superposition (TTS) principles, the $E^{*}$ values (in psi) at different temperatures and frequencies are used to develop master curves at a reference temperature, which is generally $70^{\circ} \mathrm{F}\left(21.1^{\circ} \mathrm{C}\right)$. The $E^{*}$ values at various temperatures are shifted with respect to time until the curves merge into a single smooth sigmoidal function, as given in the following equation [14]:

$$
\log \left[E^{*}\right]=\delta+\frac{\alpha}{1+e^{\beta+\gamma\left(\log t_{r}\right)}},
$$

where $t_{r}$ is the reduced time of loading at the reference temperature and sec, $\alpha, \beta, \gamma$, and $\delta$ are the parameters describing the shape of the sigmoidal function. The shift factor $\mathrm{a}(T)$ is a function of time of loading at the desired temperature $(t)$ and $t_{r}$, as shown in

$$
a(T)=\frac{t}{t_{r}} .
$$

A second-order polynomial relationship between the logarithm of the shift factor and the temperature, as shown in (6), is generally used:

$$
\log a\left(T_{i}\right)=a T_{i}^{2}+b T_{i}+c,
$$

where $a, b$, and $c$ are regression coefficients.

1.2. Significance and Objectives. As mentioned earlier, asphalt binder's rheological data are input parameters in the MEPDG. At Level 3, the $E^{*}$ master curve is estimated by using typical American Society for Testing and Materials (ASTM) A and Viscosity Temperature Susceptibility (VTS) parameters based on the asphalt binder's PG grade. At Level
$2, G^{*}$ and $\delta$ values of rotational thin film oven (RTFO)-aged binders, determined by using a DSR as per AASHTO T 315, are used as input. Furthermore, ODOT is in the process of implementing the MEPDG, which requires mechanistic data of HMA mixes with local RAPs and binders. Specifically, performance data of asphalt binders and HMA mixes with "high RAP" will have significant importance in formulating mix design guidelines with increased confidence. As illustrated earlier, previous studies (e.g., $[9,10,20]$ ) reported changes in PG of asphalt binders and/or $E^{*}$ values of mixes due to the addition of RAP. However, there exists limited research focusing on asphalt binders and mixes with high RAP content. In particular, performance data of local asphalt binders, aggregates, and RAPs currently do not exist.

The current study is aimed at fulfilling this research need while generating useful data for a better understanding of asphalt binders and mixes with high RAP contents. Consequently, the major objectives of this study are as follows: (a) evaluating the effects of high RAP on rheological and mechanistic properties of different RAP-blended binders and mixes and determining their corresponding MEPDG input parameters for conditions prevailing in Oklahoma; (b) estimating the $E^{*}$ master curves of RAP mixes from viscoelastic properties of blended asphalt binders.

\section{Materials and Methodology}

A virgin binder (PG 64-22) was collected from a refinery located in Ardmore, Oklahoma. The extraction and recovery of asphalt binders from RAP samples were conducted by following the Abson method (AASHTO T 164 followed by AASHTO T 170). Different amounts $(0,10,25,40$, and $100 \%)$ of the recovered binder were blended with the virgin binder. While mixing different amounts of the recovered binder with the virgin binder, ODOT's test specifications (OHD L-36) were followed [21]. The binder contents of the fine RAPs used in the mixes were determined by following AASHTO 308 (Standard Method of Test for Determining the Asphalt Binder Content of Hot Mix Asphalt (HMA) by the Ignition Method). In terms of blending scenarios between the virgin and RAP binders, the following three general schools of thought exist: no blending (i.e., the RAP acts like black rocks; no binder from RAP participates in mixing process), partial blending (a portion of RAP binder participates in the mixing process), and full blending (100\% of RAP binder participates in the mixing process). Since a soft virgin binder (PG 64-22) is used in preparing the hot mixes in the plant at $163^{\circ} \mathrm{C}$, a full blending of RAP binder with the virgin binder is assumed in this study. However, the exact blending scenario is very complex to understand. With the application of modern tools and techniques such as 
atomic force microscope, such experimentations can be done.

To evaluate the rheological properties of binders, Superpave binder test protocols were followed. Viscosity testing was conducted using a rotational viscometer in accordance with the AASHTO T 316 test method. To determine the PG grade of the base binder with varying amounts of recovered binders, the AASHTO M 320 test method was followed. The short-term aging of the binder was simulated in accordance with AASHTO T 240. Long-term aging was simulated using a pressure aging vessel (PAV) in accordance with AASHTO R 28. High PG and intermediate temperatures of blended binders were evaluated by conducting DSR (AASHTO T 315) tests of unaged, RTFO-aged, and PAVaged binder samples. Low PG temperatures of binder samples were validated by testing PAV-aged samples in a bending beam rheometer (BBR) in accordance with AASHTO T 313. At least three replicate samples were tested at each testing temperature to ensure repeatability of the test results.

The location of the RAP source was I-35 in McClain County (near Purcell), Oklahoma. The RAP milling site had a 1.5 inch (37 mm) overlay of HMA Type B with a PMAC-1C binder in 1994. Before 1994, the project had received a 2 inch $(50 \mathrm{~mm})$ leveling course of HMA Type $\mathrm{C}$ with an AC-3 binder in 1979. In addition to the collection of RAP millings and the virgin binder, four different types of virgin aggregates, namely, \#67 rocks, 5/8 in. chips; screenings; manufactured sand; and natural sand were collected for mix design and laboratory testing.

A total of four Oklahoma Superpave mixes, namely, an S3 (base) mix containing 25\% RAP (S3 + 25\% RAP), an S3 mix containing $40 \%$ RAP (S3 $+40 \%$ RAP), an S4 (surface) mix containing 0\% RAP (S4+0\% RAP), and an S4 mix containing $10 \%$ RAP (S4 + 10\% RAP), were prepared. Here, the $\%$ RAP in a mix denotes the portion of RAP aggregates used in the total aggregates. For instance, in the S3+25\% RAP mix, there were a $25 \%$ RAP aggregate and $75 \%$ virgin aggregates. Details of trial mix designs, aggregate consensus properties, and volumetric requirements are available in a related study [22]. The percentage of materials and corresponding gradations and volumetric properties of the final S3 and S4 mixes are presented in Table 1. The nominal maximum size (NMS) values of S3 and S4 mixes were $19 \mathrm{~mm}$ and $12.5 \mathrm{~mm}$, respectively.

The $E^{*}$ test (AASTHO TP 62) specimens were prepared from cylindrical samples. The samples were mixed at $325^{\circ} \mathrm{F}$ $\left(163^{\circ} \mathrm{C}\right)$ and compacted at $300^{\circ} \mathrm{F}\left(149^{\circ} \mathrm{C}\right)$. The $E^{*}$ testing was conducted at five different temperatures $\left(14^{\circ} \mathrm{F}\left(-10.0^{\circ} \mathrm{C}\right)\right.$, $40^{\circ} \mathrm{F} \quad\left(4.4^{\circ} \mathrm{C}\right), \quad 70^{\circ} \mathrm{F} \quad\left(21.1^{\circ} \mathrm{C}\right), \quad 100^{\circ} \mathrm{F} \quad\left(37.8^{\circ} \mathrm{C}\right)$, and $130^{\circ} \mathrm{F}$ $\left(54.4^{\circ} \mathrm{C}\right)$ ) starting at the lowest temperature and proceeding to the highest. For each temperature level, the test was conducted at six different frequencies $(25,10,5,0.5$, and $0.1 \mathrm{~Hz}$ ). Aggregates used in the mix design were predominately limestone.

The ASTM A and VTS parameters were estimated based on the PG grades, viscosity, and DSR test data for blended binders with different percentages of RAP binders. The ASTM A and VTS parameters and volumetric properties of corresponding mixes were then used to estimate $E^{*}$ values of S4 and S3 mixes. Master curves of $E^{*}$ obtained from the measured and predicted $E^{*}$ values at different temperatures were then compared.

\section{Test Results and Discussion}

3.1. Viscosity. As expected, the viscosity of the RAP binder was found to be significantly higher than the virgin binder (Table 2). Such differences decrease with a reduction of testing temperatures. For example, at $135^{\circ} \mathrm{C}$ and $165^{\circ} \mathrm{C}$, the viscosity value of the RAP binder was about 7 and 3 times, respectively, higher than that of the virgin binder. However, all blended binders met the Superpave viscosity criterion (should be less than $3 \mathrm{~Pa} \cdot \mathrm{s}$ ) for pumping and handling at $135^{\circ} \mathrm{C}$. It should be noted that the Superpave ${ }^{\circledR}$ mixture design requires that gyratory specimens be mixed and compacted at equiviscous binder temperatures corresponding to viscosities of $0.170 \pm 0.02$ and $0.280+0.03 \mathrm{~Pa} \cdot \mathrm{s}$, as recommended by ASTM D 4293 [23]. Using these viscosity values as baselines, the mixing and compaction temperatures of the base binder were found to be $156^{\circ} \mathrm{C}$ and $145^{\circ} \mathrm{C}$, respectively. The equiviscous mixing temperatures for S4 + 10\% RAP, S3 + 25\% RAP, and S3 + 40\% RAP binders were found to be $157^{\circ} \mathrm{C}, 162^{\circ} \mathrm{C}$, and $178^{\circ} \mathrm{C}$, respectively. On the other hand, the equiviscous compaction temperatures for S $4+10 \%$ RAP, S3 + 25\% RAP, and S3 + 40\% RAP binders were found to be $146^{\circ} \mathrm{C}, 151^{\circ} \mathrm{C}$, and $166^{\circ} \mathrm{C}$, respectively. Thus, the mixing temperatures of the blended binders with $10 \%$, $25 \%$, and $40 \%$ of RAP were found to be $1^{\circ} \mathrm{C}, 6^{\circ} \mathrm{C}$, and $22^{\circ} \mathrm{C}$, respectively, higher than those of the base binder. Similarly, the compaction temperatures of the blended binders with $10 \%, 25 \%$, and $40 \%$ RAP were found to be $1{ }^{\circ} \mathrm{C}, 6^{\circ} \mathrm{C}$, and $21^{\circ} \mathrm{C}$, respectively, higher than those of the base binder.

3.2. Performance Grade. The high and low critical temperatures for the base binder were found to be $64.8^{\circ} \mathrm{C}$ and $-24.1^{\circ} \mathrm{C}$, respectively. As shown in Table 2, the corresponding high temperatures for PG 64-22 + 10\% RAP, PG 64-22 + 25\% RAP, and PG $64-22+40 \%$ RAP binders were found to be $69.5^{\circ} \mathrm{C}$, $72.5^{\circ} \mathrm{C}$, and $77.8^{\circ} \mathrm{C}$, respectively. Low critical temperatures for PG 64-22 + 10\% RAP, PG 64-22 + 25\% RAP, and PG 64$22+40 \%$ RAP binders were found to be $-23.1^{\circ} \mathrm{C},-19.8^{\circ} \mathrm{C}$, and $-16.8^{\circ} \mathrm{C}$, respectively. The standard $\left(6^{\circ} \mathrm{C}\right.$ interval) Superpave PG grades of the PG 64-22 + 10\% RAP, PG 64-22 + 25\% RAP, and PG 64-22 + 40\% RAP binders were PG 64-22, PG 70-16, and PG 76-16, respectively. Li et al. [9] reported similar findings in their study, which evaluated the high PG temperatures of the extracted binders from ten RAP mixes. In all mixes, the high PG temperature was found to increase by one or two grades with the addition of RAP or millings; each of the binders increased from a PG 58-XX to either a PG 64-XX or a PG 70XX. A study [9], however, reported that the recovered binders from the RAP mixes (up to $40 \%$ RAP) were stiffer than the recovered binders from the 100\% RAP. McGraw et al. [12] also reported increased high- and low-temperature PG grades with an increase in the RAP content in new mixes. The PG grades of recovered binders from mixes (virgin binder PG 58-28) with 
TABLE 1: Gradation and volumetric properties of S3 and S4 mixes.

\begin{tabular}{|c|c|c|c|c|c|c|}
\hline \multirow{2}{*}{ Blended material } & \multirow{2}{*}{$\mathrm{S} 3+25 \%$ RAP } & \multirow{2}{*}{$\mathrm{S} 3+40 \% \mathrm{RAP}$} & \multirow{2}{*}{ Gradation $(\mathrm{mm})$} & \multicolumn{3}{|c|}{$\%$ passing } \\
\hline & & & & $\mathrm{S} 3+25 \%$ RAP & $\mathrm{S} 3+40 \%$ RAP & Req. $^{\mathrm{a}}$ \\
\hline \#67 rock & $15 \%$ & $12 \%$ & 25 & 100 & 100 & 100 \\
\hline 5/8" chips & $22 \%$ & $25 \%$ & 19 & 99 & 97 & $90-100$ \\
\hline Screenings & $17 \%$ & $8 \%$ & 12.5 & 89 & 90 & $\leq 90$ \\
\hline Manufactured sand & $10 \%$ & $15 \%$ & 9.5 & 78 & 70 & - \\
\hline Natural sand & $11 \%$ & $0 \%$ & 4.75 & 56 & 43 & - \\
\hline Fine RAP & $25 \%$ & $40 \%$ & 2.36 & 39 & 24 & $23-49$ \\
\hline$G_{m m}$ & 2.533 & 2.475 & 1.18 & 31 & 16 & - \\
\hline$G_{s e}$ & 2.722 & 2.665 & 0.6 & 25 & 11 & - \\
\hline$G_{s b}$ & 2.671 & 2.628 & 0.3 & 18 & 7 & - \\
\hline$G_{b}$ & 1.01 & 1.01 & 0.15 & 9.0 & 5 & - \\
\hline Virgin PG binder & $64-22$ & $64-22$ & 0.075 & 5.2 & 2.7 & $2-8$ \\
\hline Total $P_{\mathrm{b}}(\%)$ & 4.4 & 4.7 & LA abrasion (\%) & 21 & 22 & $\leq 40$ \\
\hline Virgin $P_{\mathrm{b}}(\%)$ & 2.9 & 2.9 & Micro-Deval (\%) & 11.8 & 12.5 & $\leq 25$ \\
\hline VMA (\%) (req.: $\geq 13.0$ ) & 14.5 & 15.2 & Sand equiv. (\%) & 78 & 82 & $\geq 40$ \\
\hline VFA (\%) (req.: 65-78) & 67.2 & 73.6 & FAA $(\%)$ & 43.5 & 42 & $\geq 40$ \\
\hline $\mathrm{DP}$ (req.: 0.6-1.2) & 1.4 & 0.8 & TSR & 0.87 & 0.82 & $\geq 80$ \\
\hline- & - & & A rut $(\mathrm{mm})$ & 1.1 & 3.6 & $\leq 6 \mathrm{~mm}$ \\
\hline - & - & Perme & bility $\left(10^{-5} \mathrm{~cm} / \mathrm{s}\right)$ & 6.4 & 6.5 & $\leq 12.5$ \\
\hline \multirow{2}{*}{ Blended material } & \multirow{2}{*}{ S4 + 0\% RAP } & \multirow{2}{*}{ S4 + 10\% RAP } & \multirow{2}{*}{ Gradation $(\mathrm{mm})$} & \multicolumn{3}{|c|}{$\%$ passing } \\
\hline & & & & $\mathrm{S} 4+0 \% \mathrm{RAP}$ & S4 + 10\% RAP & Req. $^{\text {a }}$ \\
\hline 5/8" chips & $25 \%$ & $30 \%$ & 19 & 100 & 100 & $90-100$ \\
\hline $1 / 2$ " chips & $18 \%$ & $0 \%$ & 12.5 & 96 & 98 & $\leq 90$ \\
\hline Screenings & $42 \%$ & $22 \%$ & 9.5 & 88 & 90 & - \\
\hline Manufactured sand & $0 \%$ & $33 \%$ & 4.75 & 57 & 68 & - \\
\hline Natural sand & $15 \%$ & $5 \%$ & 2.36 & 35 & 39 & $23-49$ \\
\hline Fine RAP & $0 \%$ & $10 \%$ & 1.18 & 28 & 25 & - \\
\hline$G_{m m}$ & 2.488 & 2.470 & 0.6 & 23 & 17 & - \\
\hline$G_{s e}$ & 2.699 & 2.687 & 0.3 & 15 & 10 & - \\
\hline$G_{s b}$ & 2.670 & 2.605 & 0.15 & 7 & 6 & - \\
\hline$G_{b}$ & 1.01 & 1.01 & LA abrasion (\%) & 18 & 21 & $\leq 40$ \\
\hline Virgin PG binder & $64-22$ & $64-22$ & FAA (\%) & 42.7 & 41.6 & $\geq 40$ \\
\hline Total $P_{\mathrm{b}}(\%)$ & 5.1 & 5.3 & Micro-Deval (\%) & 7.7 & 11.8 & $\leq 25$ \\
\hline Virgin $P_{\mathrm{b}}(\%)$ & 5.1 & 4.8 & Sand equiv. (\%) & 67 & 75 & $\geq 40$ \\
\hline VMA (req.: $\geq 14.0$ ) & 15.8 & 15.9 & TSR & 0.85 & 0.82 & $\geq 80$ \\
\hline VFA (req.:65-78) & 69.6 & 73.3 & APA rut $(\mathrm{mm})$ & 1.39 & 4.2 & $\leq 6 \mathrm{~mm}$ \\
\hline $\mathrm{DP}$ (req.: $0.6-1.2$ ) & 0.97 & 0.6 & Permeability $\left(10^{-5} \mathrm{~cm} / \mathrm{s}\right)$ & 3 & 10.4 & $\leq 12.5$ \\
\hline
\end{tabular}

${ }^{\mathrm{a}}$ Required for 0.3-3 M of design ESAL; RAP: recycled asphalt pavement; req.: required; equiv.: equivalent; $G_{m m}$ : maximum theoretical specific gravity; $G_{s e}$ : effective specific gravity of aggregates; $G_{s b}$ : bulk specific gravity of aggregates; TSR: tensile strength ratio; VMA: voids in mineral aggregates (\%); VFA: voids filled with asphalt (\%); DP: dust proportion; FAA = fine aggregates angularity; APA: asphalt pavement analyzer; $P_{b}$ : binder content.

$15 \%, 25 \%$, and $30 \%$ RAP were found to be PG 70-16, PG 76-16, and PG 70-22, respectively. Regarding the inconsistencies in the PG grade of the $30 \%$ RAP mix, subsequent inspections by the researchers [12] revealed that the RAP used in the designs of $15 \%$ and $25 \%$ RAP mixes was contaminated by the presence of crack filler material, which was removed during the design of the $30 \%$ RAP mix.

Based on the limiting Superpave rutting factors ( $\geq 1.0 \mathrm{kPa}$ under unaged and $\geq 2.2 \mathrm{kPa}$ under RTFO-aged samples) and fatigue factor $(\leq 5000 \mathrm{kPa}$ under PAV-aged samples) obtained from DSR tests, and stiffness $(\leq 300 \mathrm{MPa})$ and $\mathrm{m}$ value $(\geq 0.300)$ obtained from BBR tests, blending charts for high, intermediate, and low critical temperatures were established (Figure 1). These blending charts can be used to determine the appropriate amount of RAP to be used when the properties of virgin and recovered binders are known [24]. Also, for a given
RAP content and recovered binder's critical temperatures, the PG grade of the virgin binder can be obtained. It is also evident from Figure 1 that the fatigue critical temperature decreases with the increase of the RAP content, which is expected as the RAP binder is significantly stiffer than the virgin binder.

3.3. MEPDG Level 1 and 2 Inputs. The variations of MEPDG Level 1 or Level 2 inputs with different RAP contents are shown in Figure 2. A general trend is that the $G^{*}$ value decreased and the $\delta$ value increased with an increase of testing temperature irrespective of the RAP binder content with an exception of $10 \%$ RAP at lower testing temperatures $\left(21.1^{\circ} \mathrm{C}\right.$ and $\left.29.4^{\circ} \mathrm{C}\right)$. With similar exceptions, another trend is that the $G^{*}$ value increased and the $\delta$ value decreased with an increase of the RAP binder, indicating an increase in stiffness of the blended binder compared to the virgin 
TABle 2: Performance grade and viscosity of blended binders.

\begin{tabular}{|c|c|c|c|c|c|c|}
\hline \multicolumn{7}{|l|}{ Performance grade } \\
\hline \multirow[t]{2}{*}{ Binder type } & \multicolumn{2}{|c|}{$\begin{array}{c}\text { High critical } \\
\text { temperature }\left({ }^{\circ} \mathrm{C}\right)\end{array}$} & \multicolumn{2}{|c|}{$\begin{array}{l}\text { Low critical } \\
\text { temperature }\end{array}$} & \multirow[t]{2}{*}{ High and low critical temperature } & \multirow[t]{2}{*}{ Superpave PG grade } \\
\hline & Unaged & RTFO-aged & $m$ value & $S$ value & & \\
\hline PG 64-22 & 64.9 & 64.8 & -24.1 & -26.6 & $64.8,-24.1$ & PG 64-22 \\
\hline $\mathrm{RAP}^{*}$ & 98.1 & 99.2 & -14.6 & -20.2 & $98.1,-14.6$ & PG 94-10 \\
\hline PG $64-22+10 \%$ RAP & 69.6 & 69.5 & -23.1 & -25.9 & $69.5,-23.1$ & PG $64-22$ \\
\hline PG $64-22+25 \%$ RAP & 73.1 & 72.8 & -19.8 & -22.3 & $72.5,-19.8$ & PG $70-16$ \\
\hline PG $64-22+40 \%$ RAP & 77.8 & 78.2 & -16.8 & -18.5 & $77.8,-16.8$ & PG 76-16 \\
\hline \multicolumn{7}{|c|}{ Viscosity data (MPa.s) at different temperatures } \\
\hline Binder type & Aging & condition & $135^{\circ} \mathrm{C}$ & $150^{\circ} \mathrm{C}$ & $165^{\circ} \mathrm{C}$ & $180^{\circ} \mathrm{C}$ \\
\hline \multirow{2}{*}{ PG 64-22 } & \multicolumn{2}{|c|}{ Unaged } & 424 & 219 & 125 & 79 \\
\hline & \multicolumn{2}{|c|}{ RTFO-aged } & 595 & 260 & 156 & 88 \\
\hline \multirow{2}{*}{$\mathrm{RAP}^{* *}$} & \multicolumn{2}{|c|}{ Unaged } & 3838 & 1438 & 613 & 300 \\
\hline & \multicolumn{2}{|c|}{ RTFO-aged } & $\mathrm{N} / \mathrm{A}$ & N/A & N/A & N/A \\
\hline \multirow{2}{*}{ PG $64-22+10 \%$ RAP } & \multicolumn{2}{|c|}{ Unaged } & 450 & 225 & 125 & 75 \\
\hline & \multicolumn{2}{|c|}{ RTFO-aged } & 610 & 265 & 159 & 90 \\
\hline \multirow{2}{*}{ PG $64-22+25 \%$ RAP } & \multicolumn{2}{|c|}{ Unaged } & 588 & 292 & 152 & 100 \\
\hline & \multicolumn{2}{|c|}{ RTFO-aged } & 1124 & 445 & 333 & 135 \\
\hline \multirow[b]{2}{*}{ PG $64-22+40 \%$ RAP } & \multicolumn{2}{|c|}{ Unaged } & 1023 & 594 & 290 & 160 \\
\hline & \multicolumn{2}{|c|}{ RTFO-aged } & 2412 & 1071 & 554 & 276 \\
\hline
\end{tabular}

*BBR tests on the RAP binder were conducted under "As-Is" condition as it already went through oxidative hardening in its service life. ${ }^{* *}$ Rotational viscosity test was not conducted on the RAP binder under the RTFO-aged condition.

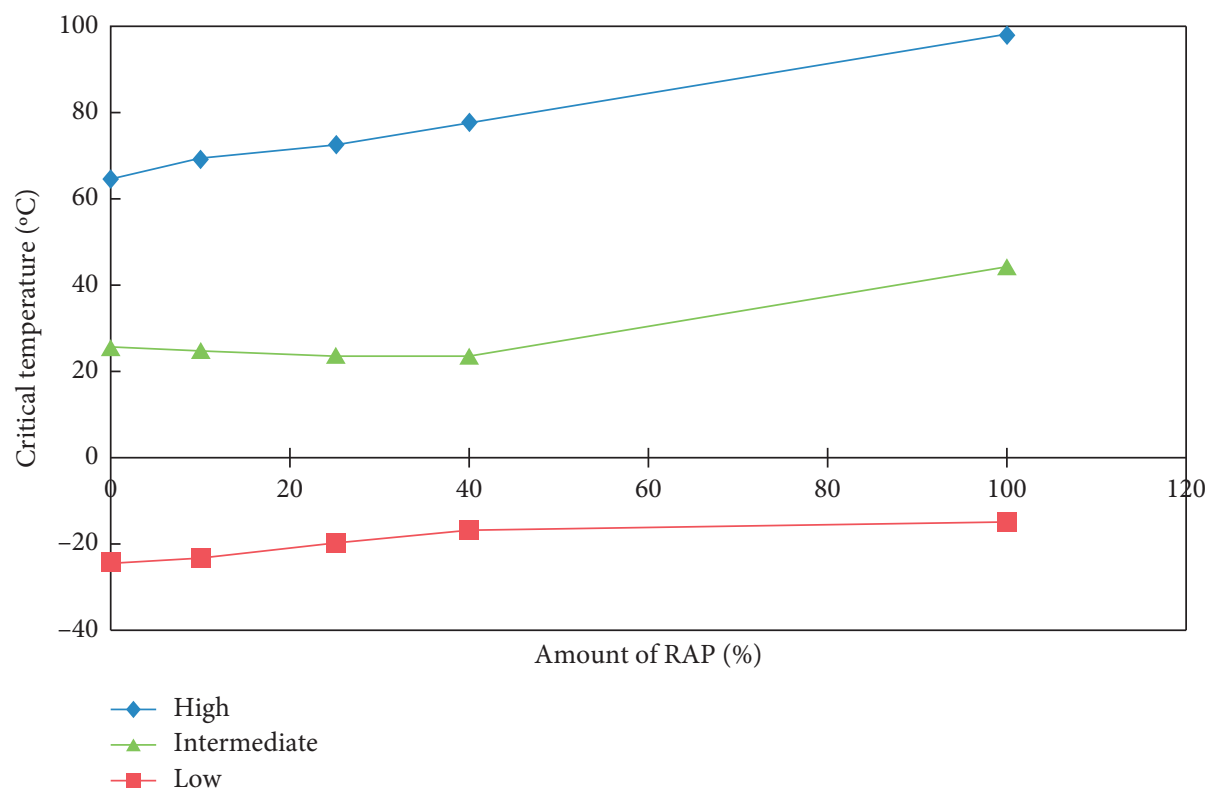

FIGURE 1: Blending chart for binders with RAP.

binder. Such an increase in stiffness had been reflected in the PG grade of the blended binders, as illustrated earlier. One possible reason for such discrepancies (higher $G^{*}$ and lower $\delta$ values) for $10 \%$ RAP-modified binders at lower testing temperatures $\left(21.1^{\circ} \mathrm{C}\right.$ and $\left.29.4^{\circ} \mathrm{C}\right)$ could be associated with the operator errors. 


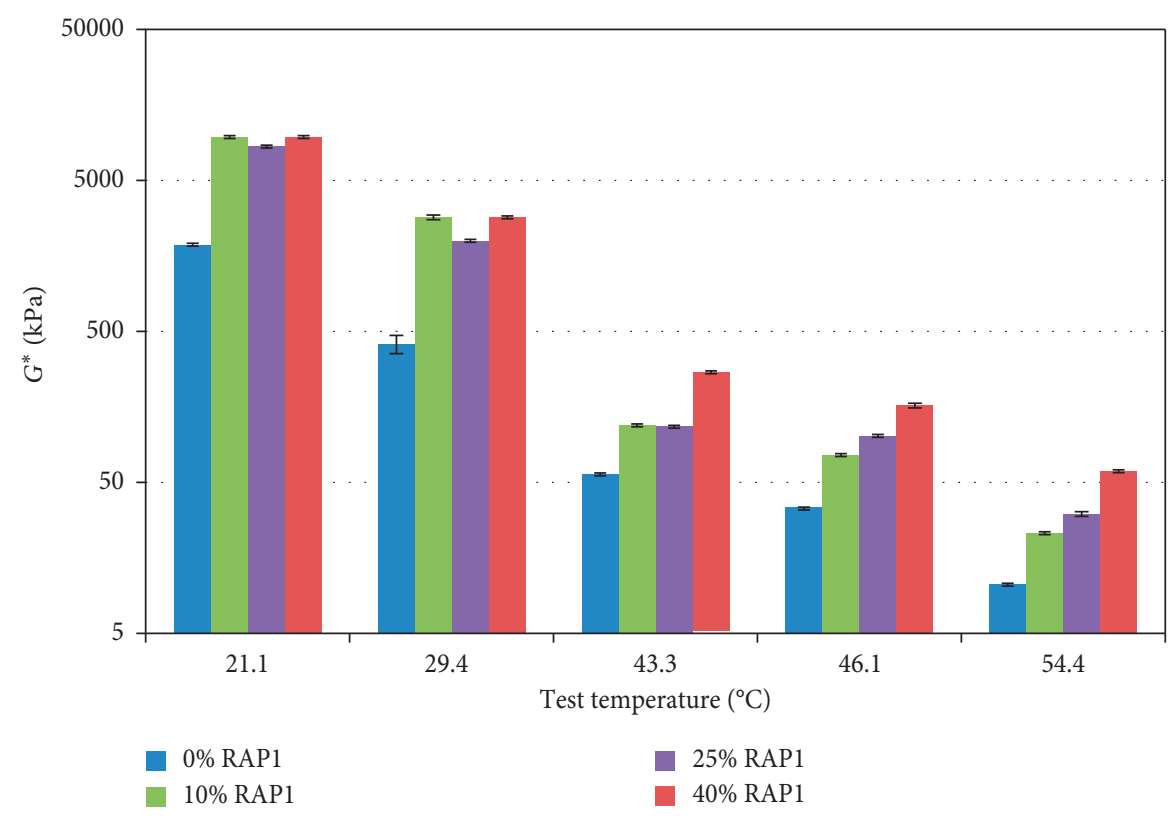

(a)

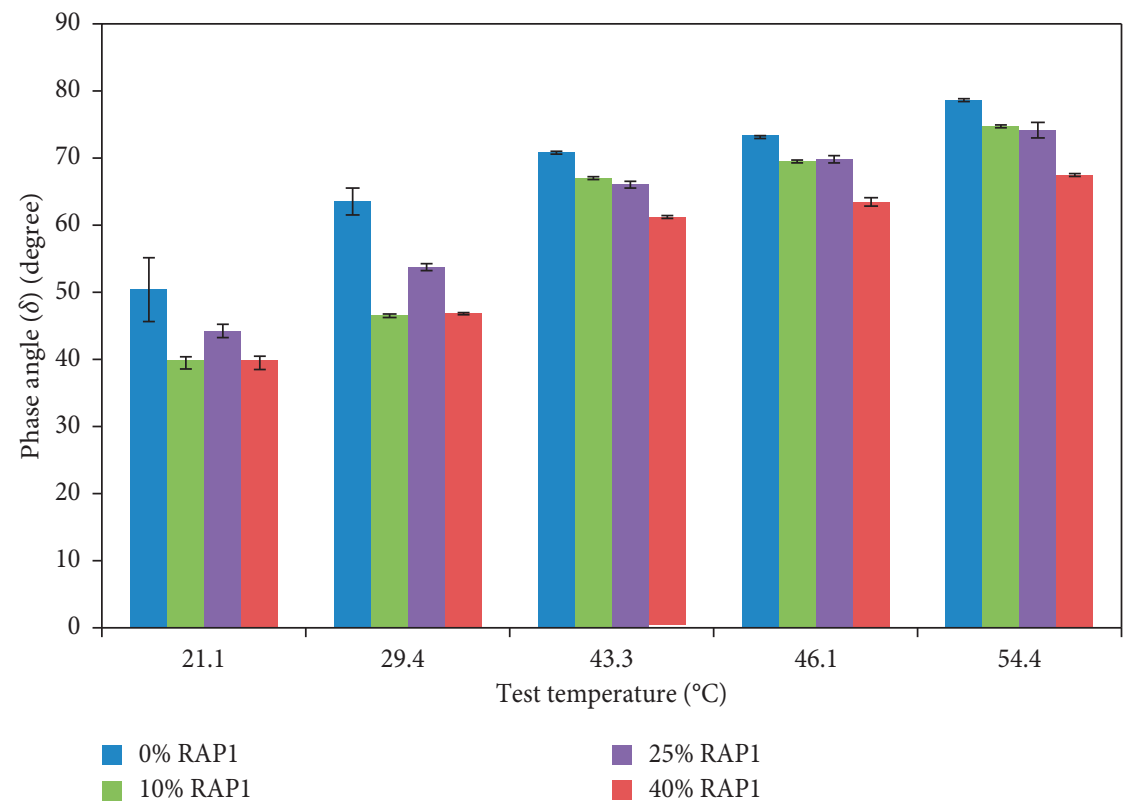

(b)

FIgURE 2: MEPDG input parameters based on DSR tests: (a) $G^{*}$ and (b) phase angle.

3.4. Prediction of $E^{*}$ Values. The $E^{*}$ values of the S4 and S3 mixes were predicted by using (1). The $E^{*}$ master curves for these mixes were then constructed using the TTS principle at a reference temperature of $21.1^{\circ} \mathrm{C}\left(70^{\circ} \mathrm{F}\right)$, as recommended by the MEPDG. As shown in Figure 3(a), the $E^{*}$ data at all temperatures, other than the reference temperature, were shifted with respect to time until the $E^{*}$ curves merged into a single smooth sigmoidal function. The master curve was constructed by using a second-order polynomial relationship (6) between the logarithm of the shift factors $\left(\log a\left(T_{i}\right)\right)$ and the temperature. An example of a shift factor versus the reduced log time is shown in Figure 3(b). It is evident from Figure 3(a) that the $E^{*}$ value increases as the loading time decreases (frequency increases), while it decreases as the testing temperature increases. For example, at $40^{\circ} \mathrm{F}$, the $E^{*}$ values of the $\mathrm{S} 3+40 \%$ RAP increase from $1513 \mathrm{ksi}$ (at $10 \mathrm{sec}$ or $0.1 \mathrm{~Hz}$.) to $2870 \mathrm{ksi}$ (at $0.04 \mathrm{sec}$ or $25 \mathrm{~Hz}$.). On the other hand, at a constant loading time of 1 


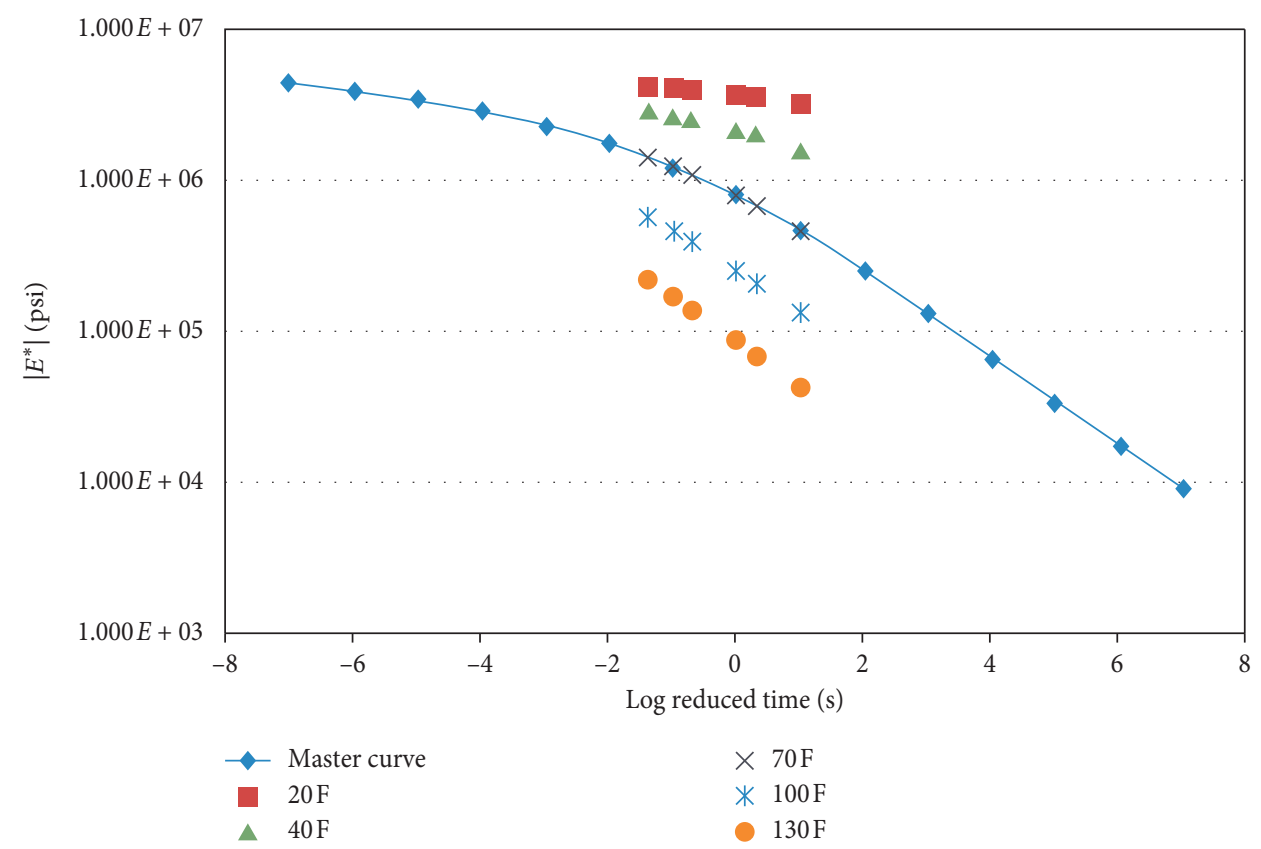

(a)

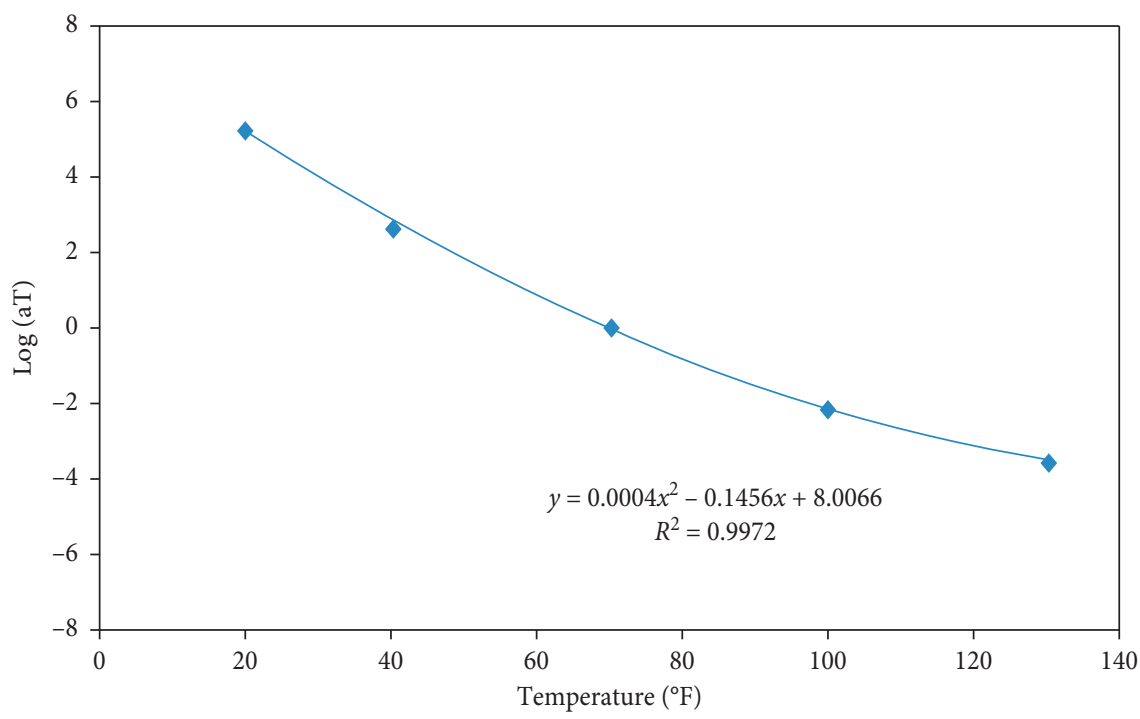

(b)

Figure 3: Examples of (a) predicted $E^{*}$ master curve for S3 + 40\% RAP and (b) shift factor.

sec (one $\mathrm{Hz}$ ), the $E^{*}$ value decreases from 2069 (at $40^{\circ} \mathrm{F}$ ) to $85 \mathrm{ksi}\left(\right.$ at $\left.130^{\circ} \mathrm{F}\right)$. This behavior is consistent with the observations made by Flintsch et al. [25]. This study reported that, at $70^{\circ} \mathrm{F}\left(21.1^{\circ} \mathrm{C}\right)$ and a loading frequency of $25 \mathrm{~Hz}$, the measured $E^{*}$ values for mixes with $12 \%, 15 \%$, and $20 \%$ RAP were found to be $787 \mathrm{ksi}, 1,197 \mathrm{ksi}$, and $1,362 \mathrm{ksi}$, respectively.

3.5. Effect of RAP Content. The $E^{*}$ master curves for the mixes with different percentages of RAP of the current study are shown in Figure 4 . In general, the $E^{*}$ values increase with an increase in the RAP content in both S4 and S3 mixes. It is seen from Figure 4 (a) that the $E^{*}$ values of S4 $+10 \%$ RAP are significantly higher than that of the mix containing no RAP ( $\mathrm{S} 4+0 \%$ RAP). For example, the S $4+10 \%$ RAP mix yielded $E^{*}$ values approximately $34 \%$, $44 \%, 54 \%$, and $64 \%$ higher at a reduced frequency of -3 , $-1,1$, and $3 \mathrm{sec}$, respectively, as compared to the $\mathrm{S} 4+0 \%$ RAP mix. The $E^{*}$ values of S3 mixes showed a similar trend (Figure 4(b)). For example, the S3+40\% RAP mix exhibited $E^{*}$ values that are approximately $37 \%, 32 \%$, $44 \%$, and $50 \%$ higher at a log reduced time of $-3,-1,1$, and $3 \mathrm{sec}$, respectively, as compared to the corresponding $\mathrm{S} 3+25 \%$ RAP mix. Thus, the asphalt binder PG grade has a significant effect on the $E^{*}$ value for the entire temperature and frequency range. As explained earlier, the PG grades of the base binder with $25 \%$ and $40 \%$ RAP yielded a 


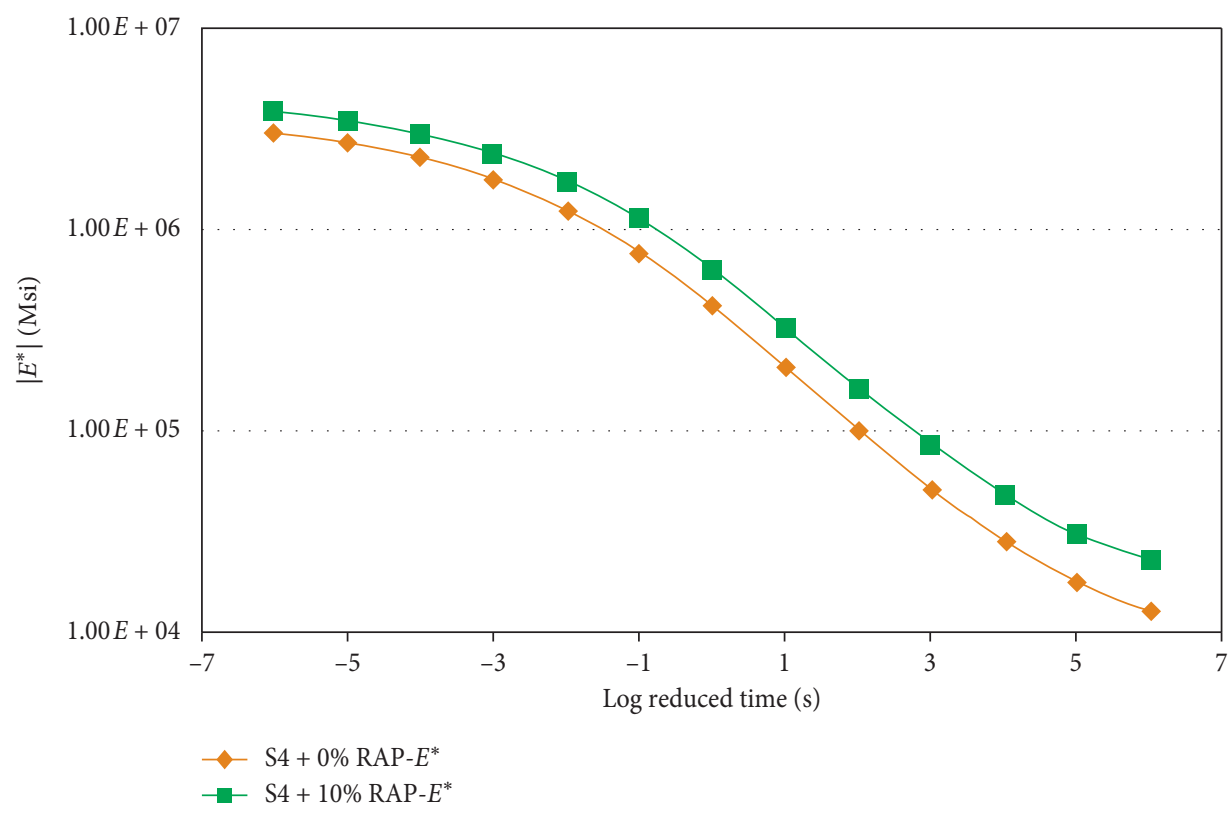

(a)

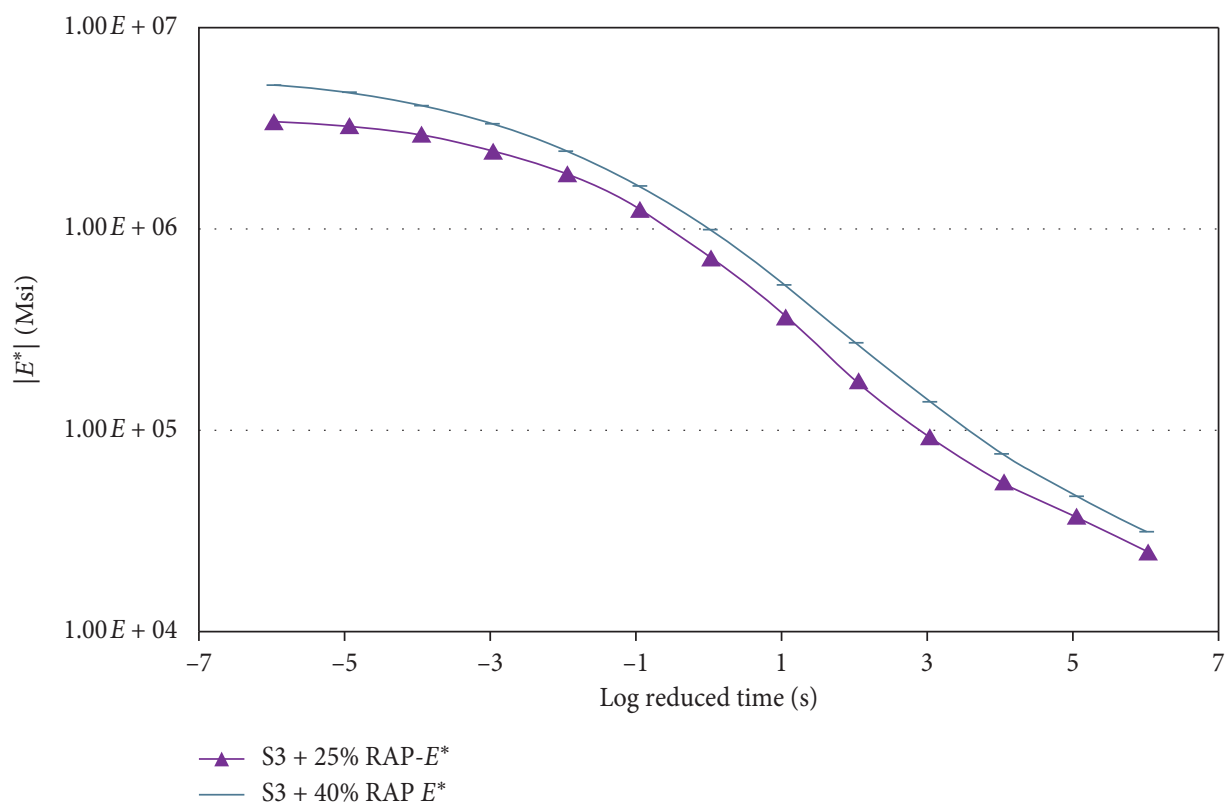

(b)

Figure 4: Comparison of $E^{*}$ master curves: (a) S4 mixes and (b) S3 mixes.

PG 70-16 and a PG 76-16 binder, respectively. Similar observations were made by other researchers in their corresponding studies (e.g., [26-28]); the $E^{*}$ value increased as the RAP content increased. McGraw et al. [12] reported significantly higher $E^{*}$ values for $30 \%$ RAP mix when compared to the control mix (no RAP); these differences are reported to be more pronounced at the lower frequencies (higher temperatures) than the higher frequencies (lower test temperatures). Kim et al. [29] also reported that the higher percentage of RAP mix had better rut-resistance due to an increase in the stiffness of the binder.
3.6. Master Curve Prediction from Binder Test Data. The $E^{*}$ master curves of the tested S4 and S3 mixes having different percentages of RAP were predicted using viscoelastic data of the blended binders and volumetric properties of the corresponding mixes. The following three types of viscoelastic data, applicable for Superpave mixes in the Witczak model, were considered: typical ASTM A (intercept) and VTS (slope) parameters, RV test data of RTFO-aged binder, and DSR test data of RTFO-aged binder. The measured and predicted $E^{*}$ master curves for S4 and S3 mixes are shown in Figures 4 and 5, respectively. As seen from Figures 4 and 5 the predicted $E^{*}$ values from the typical ASTM A and VTS 


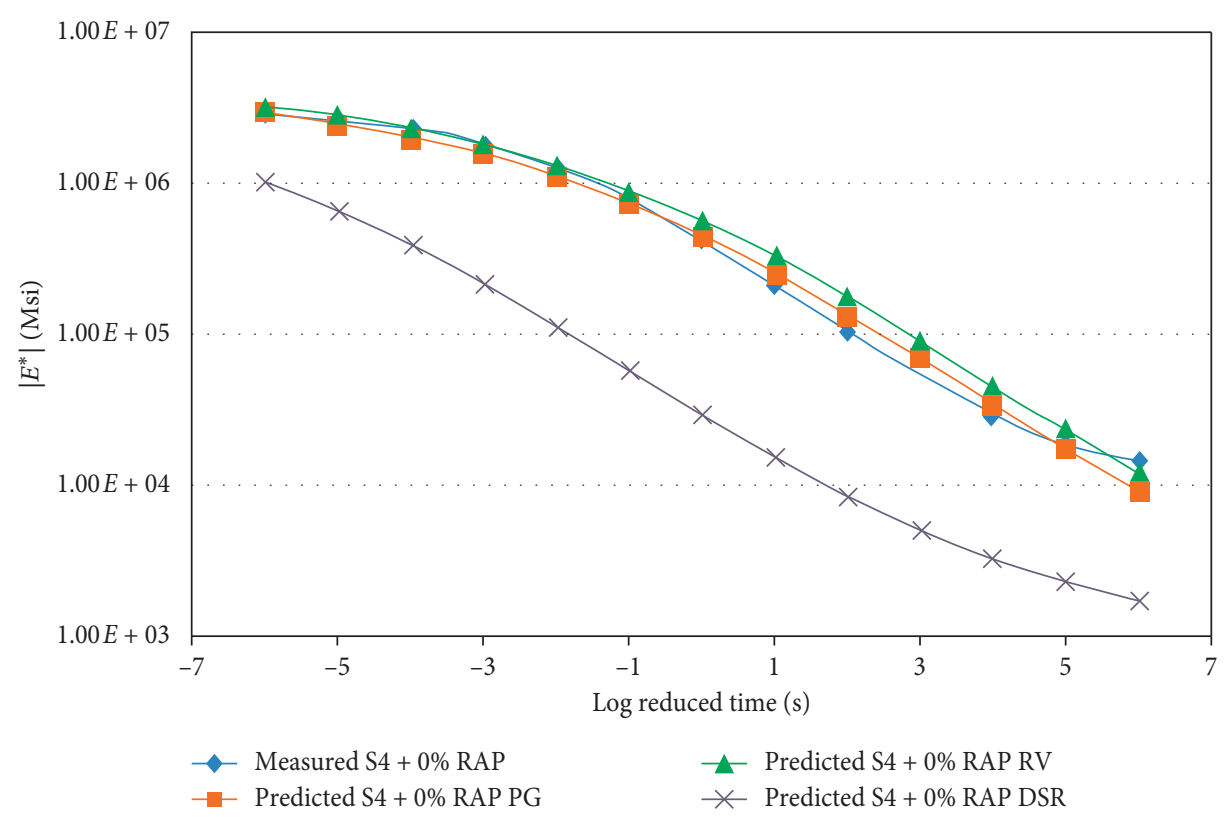

(a)

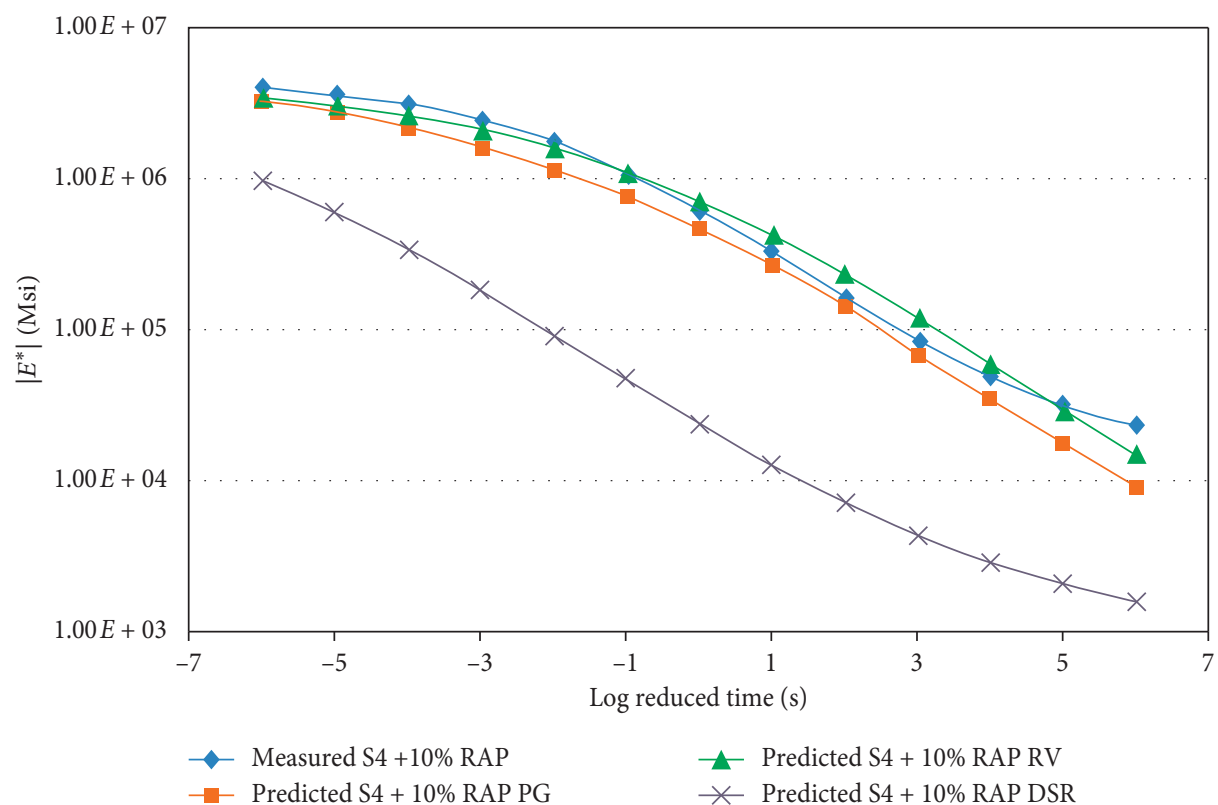

(b)

Figure 5: $E^{*}$ master curves for S4 mixes: (a) S4 + 0\% RAP and (b) S4 + 10\% RAP.

parameters are closely in agreement with the measured $E^{*}$ values with loading time (log reduced) ranging from -5 to $5 \mathrm{sec}$ irrespective of mix type and amount of RAP. Thus, the default dynamic modulus prediction equation, based on PG grades of the blended binders and volumetric data of RAP mixes, could be used for the design of low and medium traffic volume pavements.

As shown in Figure 5, the ratios of the predicted (through the Superpave PG grade) and measured $E^{*}$ values for $\mathrm{S} 4+0 \% \mathrm{RAP}$ and $\mathrm{S} 4+10 \%$ RAP vary in the ranges from 0.72 to 1.27 and from 0.42 to 0.85 , respectively. The S3 mixes exhibited similar trends (Figure 6). It is also seen from these figures that the $E^{*}$ values predicted from DSR test data are significantly lower than the measured $E^{*}$ values, while the $\mathrm{RV}$ test data predicted slightly higher $E^{*}$ values compared to the measured ones. The significant variations between the $E^{*}$ values estimated from DSR or RV test data and the measured $E^{*}$ values could be related to a lack of consideration of low service temperature performance of the binders. Similar observations were made by Birgisson et al. [30] for HMA mixes in Florida. That study reported that the predicted $E^{*}$ values from DSR data were significantly lower than the measured $E^{*}$ values, but the predicted $E^{*}$ values from $\mathrm{RV}$ test data were significantly higher than the measured $E^{*}$ 


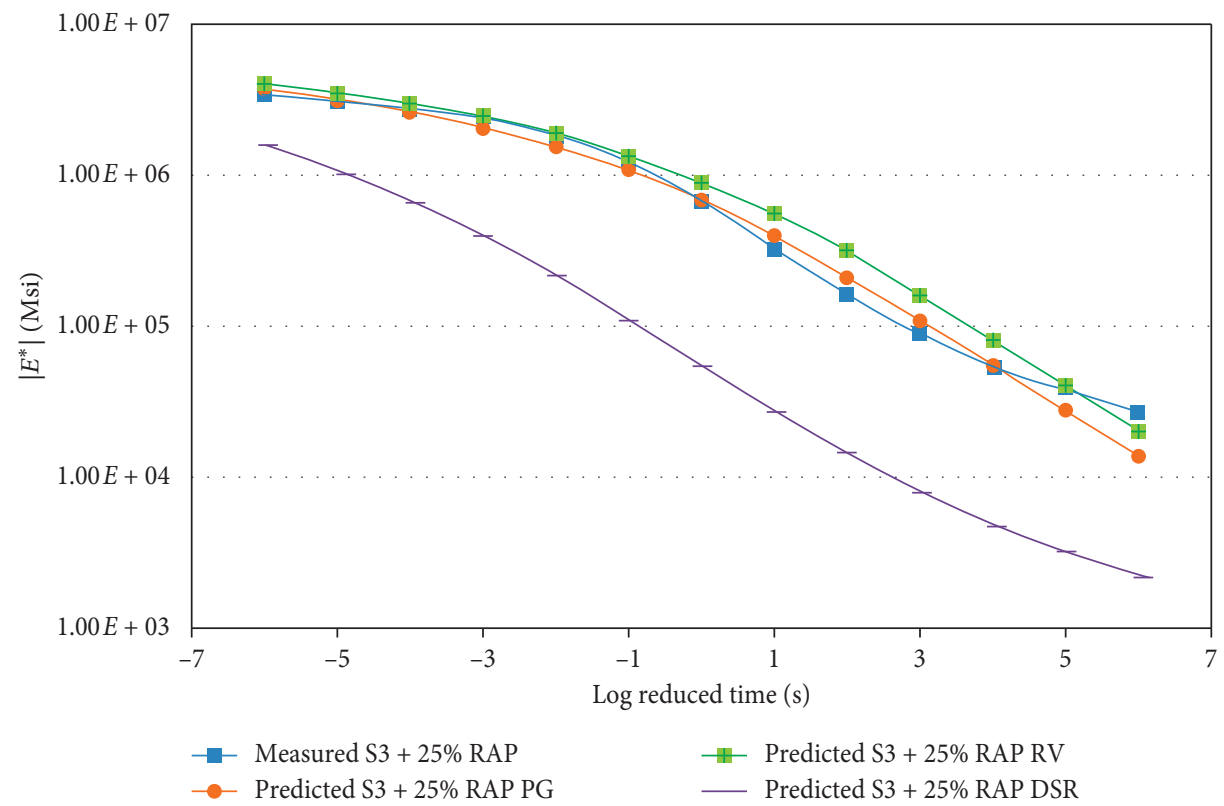

(a)

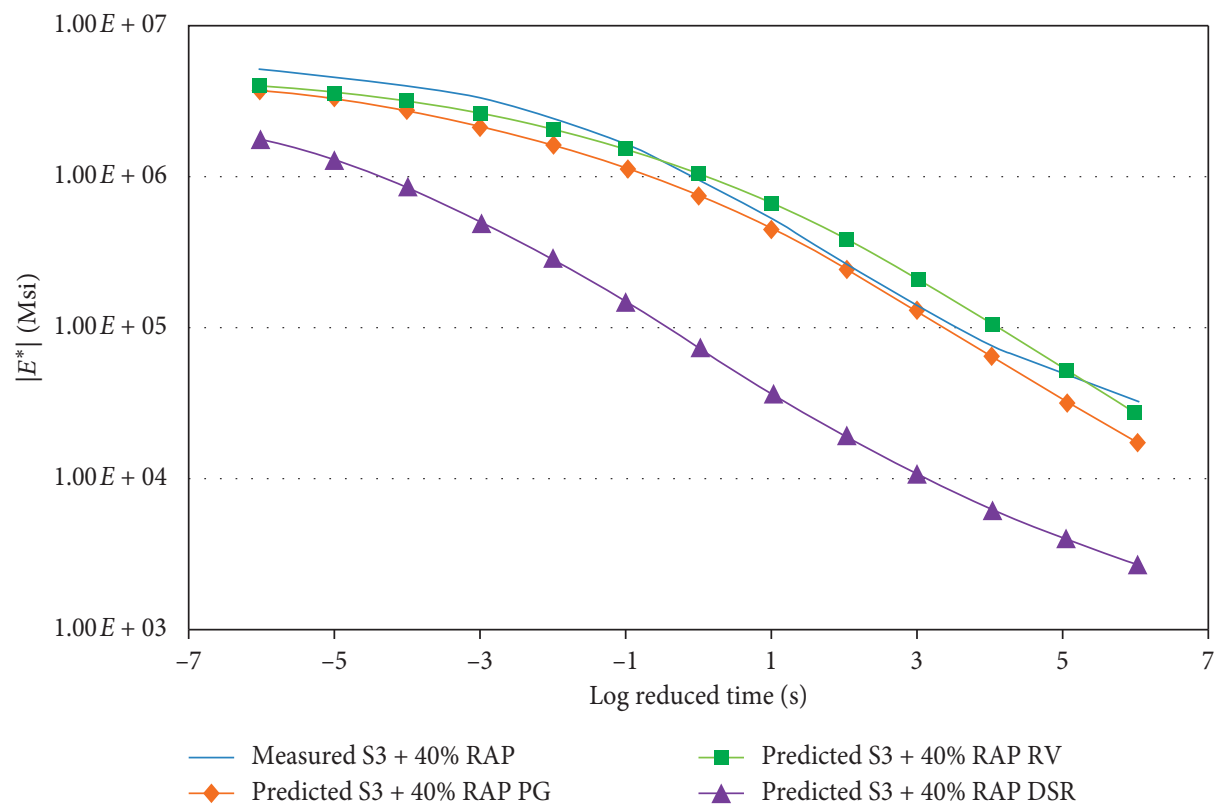

(b)

FIgURe 6: $E^{*}$ master curves for S3 mixes: (a) S3 + 25\% RAP and (b) S3 + 40\% RAP.

values. Tran and Hall [31] reported no significant difference between the measured and predicted $\mathrm{E}^{*}$ values for Arkansas HMA mixes.

3.7. Goodness-of-Fit of Master Curves. The goodness-of-fit statistics of the master curves were assessed by calculating their $R^{2}$ (correlation determination) and $S_{e} / S_{y}$ (standard error of estimate divided by standard deviation) values, with the $R^{2}$ value being a measure of model accuracy. The closer the $R^{2}$ value to 1.00 , the better the prediction. The $S_{e} / S_{y}$ value being a measure of the accuracy of the prediction indicates how well the variations of the predicted $E^{*}$ values are explainable by the predictive equations. The lower the $S_{e} / S_{y}$ value, the better the accuracy of the prediction. The minimum and maximum values of $R^{2}$ and $S_{e} / S_{y}$ of the fitted 
sigmoidal regressions were found to be 0.07 and 0.99 , respectively, indicating that $E^{*}$ master curves for all mixes had "excellent" $\left(R^{2}>0.9\right.$ and $\left.S_{\mathrm{e}} / S_{\mathrm{y}}<0.35\right)$ correlations, based on the criteria given in NCHRP Report 465 [32].

\section{Conclusions}

Based on the results presented in the preceding section, the following conclusions can be drawn [33]:

(i) The recovered binder from RAP was found to significantly more viscous than the base binder. The mixing and compaction temperatures of the blended binders with $10 \%, 25 \%$, and $40 \%$ RAP were found to be $1^{\circ} \mathrm{C}, 6^{\circ} \mathrm{C}, 22^{\circ} \mathrm{C}$ and $1{ }^{\circ} \mathrm{C}, 6^{\circ} \mathrm{C}, 21^{\circ} \mathrm{C}$, respectively, higher than those of the base binder.

(ii) The complex modulus of the blended binders and dynamic modulus of mixes with RAP were found to increase with an increase in RAP content, indicating an increase in rutting resistance for mixes with RAP. However, the low-temperature resistance of the base binder was expected to decrease with an increase in the RAP binder.

(iii) Performance grades of the selected base binder (PG 64-22) with $10 \%, 25 \%$, and $40 \%$ RAP binder were found to be PG 64-22, PG 70-16, and PG 76-16, respectively.

(iv) The dynamic modulus of the asphalt mix increases with an increase of the stiffness of the asphalt binder.

(v) The Witczak model can be used to predict $E^{*}$ master curves for mixes with RAP.

(vi) The $E^{*}$ master curves estimated from typical ASTM A and VTS parameters of the blended binders were found to be in a close agreement with those estimated from laboratory-measured $E^{*}$ values of mixes with up to $40 \%$ RAP. The DSR test data provided significantly lower $E^{*}$ values compared to the measured ones, while the rotational viscosity predicted higher $E^{*}$ values than the laboratorymeasured $E^{*}$ values.

\section{Data Availability}

The laboratory data used to support the findings of this study are included within the article. Other data used in this study are available upon request, and the request can be made to the first author at mhossain@astate.edu.

\section{Conflicts of Interest}

The authors declare that there are no conflicts of interest regarding the publication of this paper.

\section{Acknowledgments}

The authors would like to express their sincere appreciation to the Oklahoma Transportation Center (OkTC) and the Oklahoma Department of Transportation for providing financial support for this study. Sincere appreciation is also due to Dr. Pranshoo Solanki, Mr. David Adje, and Mr. Jackson Autrey, all formerly associated with the University of Oklahoma, for their assistance with laboratory testing of this study.

\section{References}

[1] FHWA, Asphalt Pavement Recycling with Reclaimed Asphalt Pavement (RAP), Federal Highway Administration, Washington, DC, USA, 2018, http://www.fhwa.dot.gov/pavement/ recycling/rap/index.cfm.

[2] C. L. Jones, Summit on Increasing RAP Use in Pavements Sate's Perspective, North Carolina Department of Transportation, Raleigh, NC, USA, 2008.

[3] E. A. O'Rear, A. Buddhala, S. Lewis, and J. Laguros, "Recycled asphalt mixes," Technical report HWY-05-05U OTC-H2r0 (001), Oklahoma Department of Transportation, Oklahoma City, OK, USA, 2008.

[4] Z. Hossain, P. Solanki, M. Zaman, S. Lewis, and K. Hobson, "Influence of recovery methods on properties of binders and aggregates recovered from recycled asphalt pavement," Journal of ASTM International, vol. 9, no. 2, 2012.

[5] R. Ghabchi, D. Sing, M. Zaman, and Z. Hossain, "Laboratory characterisation of asphalt mixes containing RAP and RAS," International Journal of Pavement Engineering, vol. 17, no. 9, 2015.

[6] NCHRP, "Guide for mechanistic-empirical design of new and rehabilitated pavement structures, final report 1-37A, part 2 design input," Material Characterization, National Cooperative Highway Research Program, Transportation Research Board, National Research Council, Washington, DC, USA, 2004.

[7] N. Soupharath, Evaluation of Rutting Resistance Characteristics of Asphalt Binder Containing Recycled Asphalt Pavement, Department of Civil \& Environmental Engineering, University of Rhode Island, South Kingstown, RI, USA, 1998.

[8] K. W. Lee, N. Soupharath, A. Shukla, C. A. Franco, and F. J. Manning, "Rheological and mechanical properties of blended asphalt containing recycled asphalt pavement binders," Journal of the Association of Asphalt Paving Technologists, vol. 68, pp. 89-125, 1999.

[9] X. Li, T. R. Clyne, and M. O. Marasteanu, "Recycled asphalt pavement (rap) effects on binder and mixture quality," Final report MN/RC-2005-02, University of Minnesota, Minneapolis, MN, USA, 2004.

[10] J. S. Daniel and A. Lachance, "Mechanistic and volumetric properties of asphalt mixtures with recycled asphalt pavement, transportation research record," Journal of the Transportation Research Board, vol. 1929, pp. 28-36, 2005.

[11] S. A. Cross and A. Jakatimath, "Determination of dynamic modulus master curves for Oklahoma HMA mixtures," Final report, Oklahoma Department of Transportation, Oklahoma City, OK, USA, 2007.

[12] J. McGraw, E. Johnson, G. Johnson, D. Linell, and M. Watson, "Incorporation of recycled asphalt singles in hot-mixed asphalt pavement mixtures," Report no. MN/RC 2010-08, Minnesota Department of Transportation, St. Paul, MN, USA, 2010.

[13] L. Loria, E. Hajj, P. Sebaaly, M. Barton, S. Kass, and T. Liske, Performance Evaluation of Asphalt Mixtures With High RAP Content, Paper No. 11-2836, Transportation Research Board Annual Meeting, Washington, DC, USA, 2011. 
[14] S. Kodippily, G. Holleran, I. Holleran, T. F. P. Henning, and D. Wilson, "Performance of recycled asphalt pavement mixes-comparing New Zealand 2 experience to American experience, 2014," in Proceedings of the Transportation Research Board Annual (93rd) Meeting, Washington, DC, USA, 2014.

[15] C. Zhang, S. Shen, and X. Jia, "Modification of the hirsch dynamic modulus prediction model for asphalt mixtures," Journal of Materials in Civil Engineering, vol. 29, no. 12, 2017.

[16] M. Islam, U. Mannan, A. S. M. Rahman, and R. Tarefder, "Effects of reclaimed asphalt pavement on hot-mix asphalt," Journal of Advances in Civil Engineering Materials, vol. 3, pp. 291-307, 2014.

[17] S. El-Badawy, R. El-Hakim, and A. Awed, "Comparing artificial neural networks with regression models for hot-mix asphalt dynamic modulus prediction," Journal of Materials in Civil Engineering, vol. 30, p. 7, 2018.

[18] M. Elkashef, S. S. Hung, D. Jones, and J. Harvey, "Using predictive models to estimate the properties of binders in reclaimed asphalt pavement mixes using fine aggregate matrix mix testing," Transportation Research Record: Journal of the Transportation Research Board, vol. 2673, no. 6, pp. 501-511, 2019.

[19] J. Bari and M. W. Witczak, "Development of a new revised version of the Witczak $E^{*}$ predictive model for hot mix asphalt mixtures," Journal of the Association of Asphalt Paving Technologists, vol. 75, pp. 381-424, 2006.

[20] Q. Dong and B. Huang, "Laboratory evaluation on resilient modulus and rate dependencies of RAP used as unbound base material," Journal of Materials in Civil Engineering, vol. 26, no. 2, 2014.

[21] ODOT, Construction Engineering, Material And Testing E-Guide, Test Data, Oklahoma Department of Transportation, Oklahoma City, OK, USA, 2017, https://www.ok.gov/odot/Doing_Business/ Construction/Materials_\&_Testing/index.html.

[22] Z. Hossain, M. Zaman, P. Solanki et al., "Implementation of MEPDG for asphalt pavements with RAP," Final report: OTCREOS10.1-45, Oklahoma Transportation Center (OkTC), Oklahoma City, OK, USA, 2013.

[23] ASTM, ASTM Standard D2493/D2493M-09 Standard Viscosity-Temperature Chart for Asphalts, ASTM International, West Conshohocken, PA, USA, 2009.

[24] NCHRP, "Recommended use of reclaimed asphalt pavement in the superpave mix design method: technician's manual," Report no. 452, National Research Council, Washington D.C, USA, 2001.

[25] G. W. Flintsch, A. Loulizi, S. D. Diefenderfer, K. A. Galal, and B. K. Diefenderfer, "Asphalt materials characterization in support of implementation of the proposed mechanisticempirical pavement design guide," Research report VTRC 07CR10, Virginia Department of Transportation, Richmond, VA, USA, 2007.

[26] M. Stroup-Gardiner and C. Wagner, "Use of RAP in Superpave HMA applications, transportation research record," Journal of Transportation Board, vol. 1681, pp. 1-9, 1999.

[27] B. Behnia, E. V. Dave, S. Ahmed, W. G. Buttlar, and H. Reis, "Effects of recycled asphalt pavement amounts on low-temperature cracking performance of asphalt mixtures using acoustic emissions," Transportation Research Record: Journal of the Transportation Research Board, vol. 2208, no. 1, pp. 64-71, 2011.

[28] R. Bonaquist, "Characterization of Wisconsin mixture low temperature properties for the Aashto mechanistic-empirical pavement design guide," Final report no. WHRP 11-12, Wisconsin Department of Transportation, Madison, WI, USA, 2011.

[29] S. Kim, T. Byron, G. Sholar, and J. Kim, Evaluation of Use of High Percentage of Reclaimed Asphalt Pavement (RAP) for Superpave Mixtures, FDOT/SMO/07-507, Florida Department of Transportation, Tallahassee, FL, USA, 2007.

[30] B. Birgisson, G. Sholar, and R. Roque, "Evaluation of predicted dynamic modulus for Florida mixtures," in Transportation Research Record, No. 1929, pp. 200-207, Transportation Research Board of the National Academies, Washington, DC, USA, 2005.

[31] N. H. Tran and K. D. Hall, "Evaluating the predictive equation in determining dynamic moduli of typical asphalt mixtures used in Arkansas," Journal of The Association of Asphalt Paving Technologist, vol. 74E, 2005.

[32] M. W. Witczak, K. Kaloush, M. El-Basyouny, and H. V. Quintus, "Simple performance test for superpave mix design, national cooperative highway research program," Report 465, Transportation Research Board of the National Academies, Washington, DC, USA, 2002.

[33] E. Hajj, P. Sebaaly, and R. Shrestha, "A laboratory evaluation of recycled asphalt pavement in HMA mixtures," Final report, University of Nevada, Reno, NV, USA, 2007. 